\title{
SURGICAL COMPLICATIONS AND UNWATED EVENTS IN THE MODERN PERCUTANEOUS VERTEBROPLASTY TREATMENT
}

\author{
Svetoslav Kalevski ${ }^{1}$, Dimitar Haritonov ${ }^{1}$, Nikolay Peev ${ }^{1}$, Evgeniya Kalevska ${ }^{2}$ \\ ${ }^{1}$ Department of Neurosurgery, Medical University of Varna, MHAT St. Anna, Varna \\ ${ }^{2}$ Department of Neurology, Medical University of Varna, UMHAT St. Marina, Varna
}

\begin{abstract}
AIM: The modern spinal surgery accepts the percutaneous vertebroplasty (PV) with polymethylmethacrylate (PMMA) as a routine procedure for treatment of painful osteoporotic, neoplastic and traumatic compression fractures in the thoracic and lumbar region of the spinal column. Although considered to be a minimally invasive and safe procedure, it could be affected by severe disabling and even life-threatening complications. The aim of the present study is to evaluate the different potential complications with their clinical presentation, diagnostics and different treatment options.

MATERIALS AND METHODS: The study analyzed a cohort of 56 consecutive patients (66 levels) treated with PV in our clinic for the period January, 2008 - July, 2012. Of them, 31 (55.4\%) were women and 25 $(44.6 \%)$ - men at a mean age of $61.7(23-80)$ years. The osteoporotic and traumatic compression fractures subgroup was comprised of $44(78.6 \%)$ patients, while the patients with neoplastic fractures were $12(21.4 \%)$. All the fractures were classified as A1 Magerl's fractures with no neurologic deficit.

RESULTS: Complications and unwanted events were registered in 9 (16.1\%) patients. Of them, 2 experienced transient increased pain syndrome intensity, one of the patients presented with index level radiculopathy, 2 patients were diagnosed with extravertebral leakage of the cement in the spinal canal with compression of the neural structures and subsequently operated, 1 patient had a cement leak in the adjacent disk, 2 patients - a cement leak in the paravertebral soft tissues and the paravertebral venous system, and one had cement pulmonary embolism.

CONCLUSION: PV is a minimally invasive and effective procedure that is used in the treatment of painful osteoporotic, traumatic and neoplastic compression fractures on neurologically intact patients. The clinically significant complications and unwanted events are a relatively rare encounter and in the majority of the cases are treatable with conservative measures. The epidural cement migration with neural elements compression is the only indication for surgical decompression and removal of the compressing cement.
\end{abstract}

Keywords: percutaneous vertebroplasty, complications, polymethylmethacrylate, treatment, clinical presentation, osteoporotic fractures

Address for correspondence:

Svetoslav Kalevski

Medical University of Varna

55 Marin Drinov Str.,

9002 Varna, Bulgaria

e-mail:dr_kalevski@abv.bg

Received: May 6, 2016

Accepted: August 16, 2016

\section{INTRODUCTION}

The percutaneous vertebroplasty (PV) with polymethylmethacrylate (PMMA) is a minimally invasive surgical procedure that has been widely used during the last decades for the treatment of painful osteoporotic fractures, pathologic neoplastic fractures (myeloma, lymphoma, hemangioma, metas- 
tasis) or traumatic vertebral compression fractures (VCF), predominantly in the thoracic and lumbar region of the spine (1-9). The technique of PV is described for the first time by Galibert and Deramond (10) in France. They first treated with PV a patient with painful C2 hemangioma in 1987.

Ten years later, PV was accepted as a clinical option in the USA as well, initially for the treatment of osteoporotic fractures and later for neoplastic and traumatic fractures $(1,8,11-13)$. In modern spinal surgery, PMMA PV is a well-accepted treatment option, which is considered as a safe and effective procedure with good outcome in up to $90 \%$ of the treated patients $(1,3,9)$. Among the biggest advantages of the VP, if compared to open surgical procedures, are minimal invasiveness, fast alleviation of the pain, reconstruction of the height of the vertebra, fast discharge, low cost, etc. $(5,14)$.

A good indication for PV are the VCF Magerl type A1, that do not respond to conservative treatment $(1,9,15)$. Absolute contraindications for PV are apparent neurological symptoms, coagulopathy, significant pulmonary or/and cardiac past medical history, infections and febrility. Relative contraindications include significant vertebral height loss, posterior vertebral body cortex involvement, dislocated bone fragment, etc. $(11,12,15,16)$. Although being a minimally invasive and safe procedure, $\mathrm{PV}$ has a rate of complication $2-10 \%$, described in published surveys $(1,2,4,6,8,11-15,17,18)$.

The extravertebral PMA leak is the most common unwanted result in patients treated with PV. Different authors report up to 70-90\% PMMA leak, especially among the patients treated with PV for osteolytic fractures $(2,7,8,14,16)$. However, the extravertebral amount is not significant enough to present clinically. The cement extravasation could be in any direction - spinal canal, intervertebral foramina, paravertebral soft tissues, adjacent intervertebral discs, or the paravertebral venous system. This could cause the majority of the clinically significant complications like radicular symptoms, cord compression, pulmonary embolism, dysphagia, etc. Among the rare complications are also fractured pedicles, ribs or sternum, pneumothorax, fat emboli, discitis, infections, CSF leaks, soft tissue hematomas, allergic reactions, etc. $(8,11,12,15)$. The majority of the complications do not require open surgery revision, however, in some cases that could also be considered $(2,4,6,18)$.

The aim of our investigation is to establish the rate, type, clinical picture, and the diagnostic and treatment options for the different complications.

\section{MATERIALS AND METHODS}

We have retrospectively investigated 56 consecutive patients after PV at 66 levels in total (Th5 - L4) treated in our clinic for the last three years. Of them,

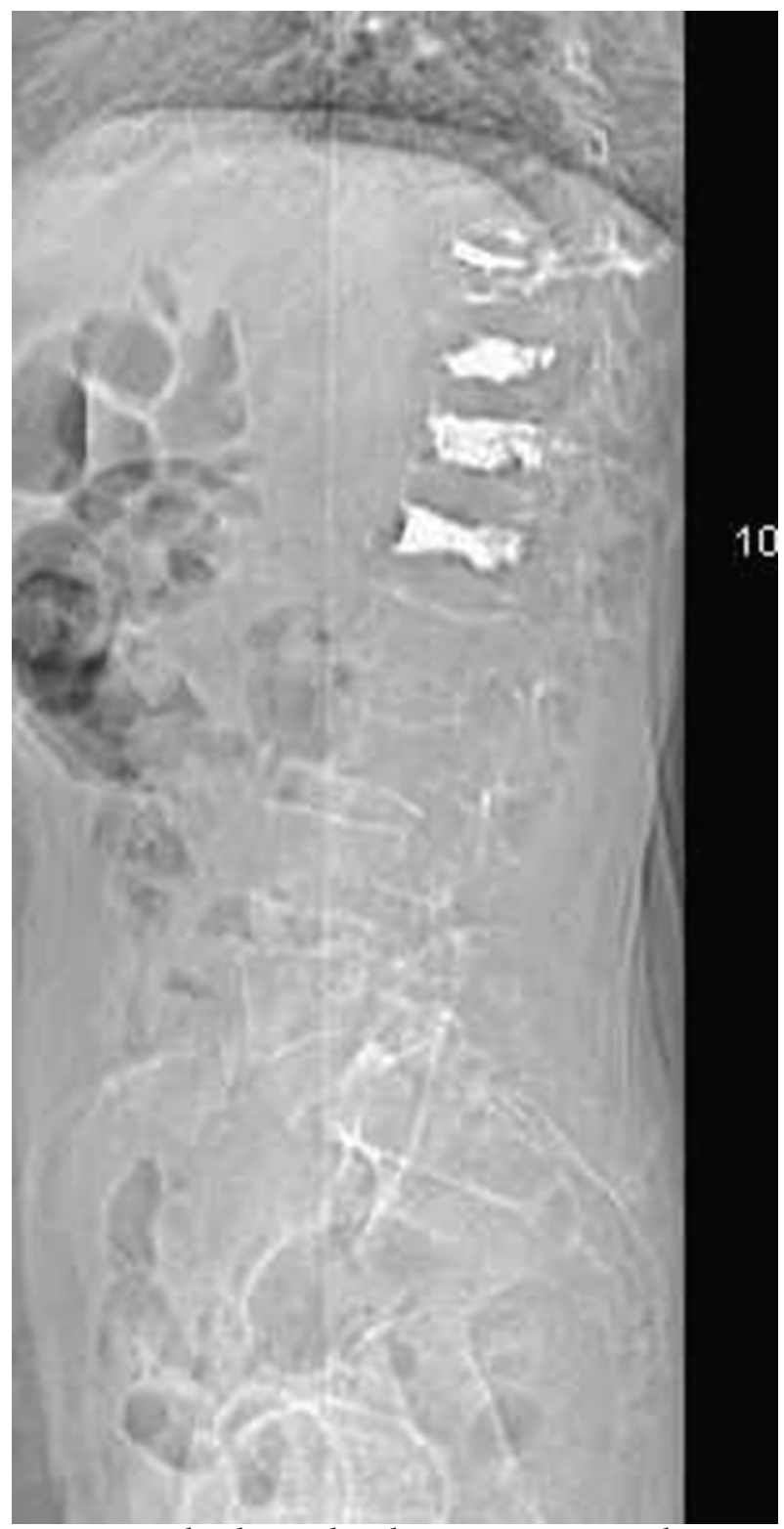

Fig. 1. Four levels vertebroplasty in a patient with osteoporotic fractures 
31 (55.4\%) were females and 25 (44.6\%) were males at a mean age of $61.7(23-80)$ years. The majority of the patients in the investigated cohort $44(78.6 \%)$ were treated for traumatic or osteoporotic or traumatic compression fractures, while 12 (21.4\%) were treated for neoplastic pathologic vertebral collapse.

All the fractures were classified as stable, type A1 (Magerl), with no neurological deficit. As indication for PV were considered acute or chronic compression fractures with pronounced pain syndrome, resistant to conservative measures. The treatment aim was to stabilize the segment and to prevent further vertebral body collapsing, together with faster mobilization and maximal pain control. Single level PV is done in 47 patients, two levels are addressed in 8 patients (4 osteoporotic fractures and 4 neoplastic fractures). Three levels are addressed in one patient with osteoporotic fractures (Fig. 1). Prior to PV, all the patients were examined with standard X-rays, CT or MRI.

The PV procedure is performed in a prone position under general anaesthesia. Intraoperative image intensifier is used to match the levels to the preoperative imaging. The body of the collapsed vertebra is reached by a bilateral transpedicular approach. The Jamshidi needle is inserted towards the

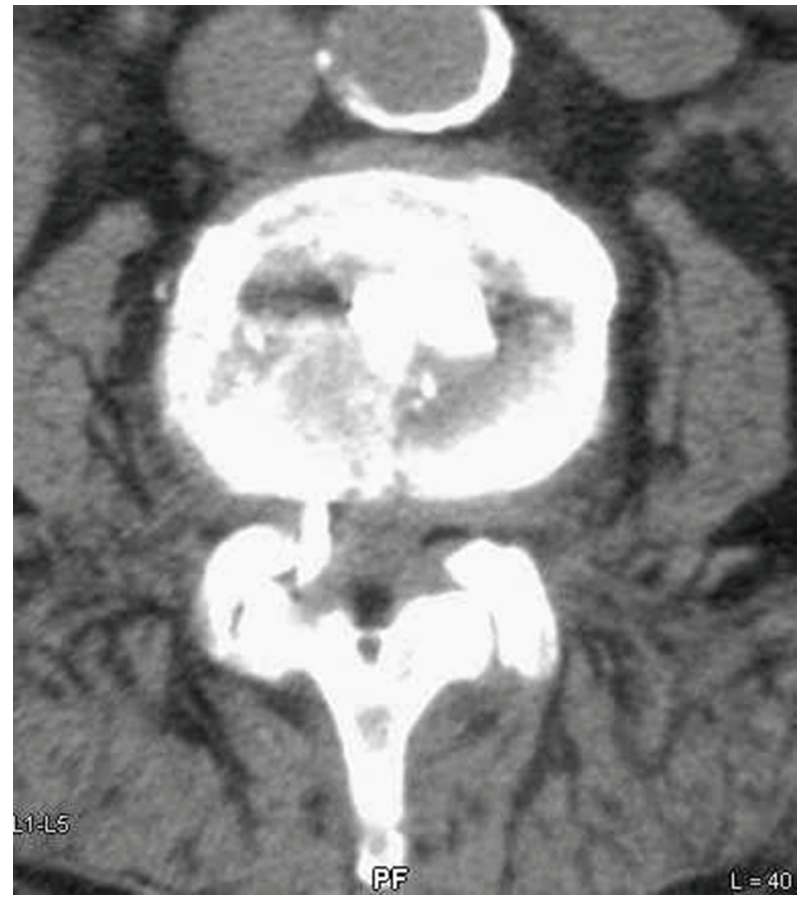

midline to reach the anterior third of the vertebra. Small amount of PMMA (usually about $1 \mathrm{ml}$ ) is injected in order to identify the direction of the potential cement leak, with respect to the posterior wall of the vertebral body. If there is not a dangerous PMMA leak, 2-10ml of PMMA are injected under average pressure. PMMA extravasation, especially a high amount, is an indication for termination of the procedure. At the end of the procedure, prior to the extraction of the Jamshidi needle, it is crucial to insert the trocar in order to push the cement from the needle into the body and to prevent leakage in the soft tissues, as that could also contribute to severe postoperative pain. In the acute postoperative period, we usually monitor the neurovascular status, and also the wound every 30 minutes. If there

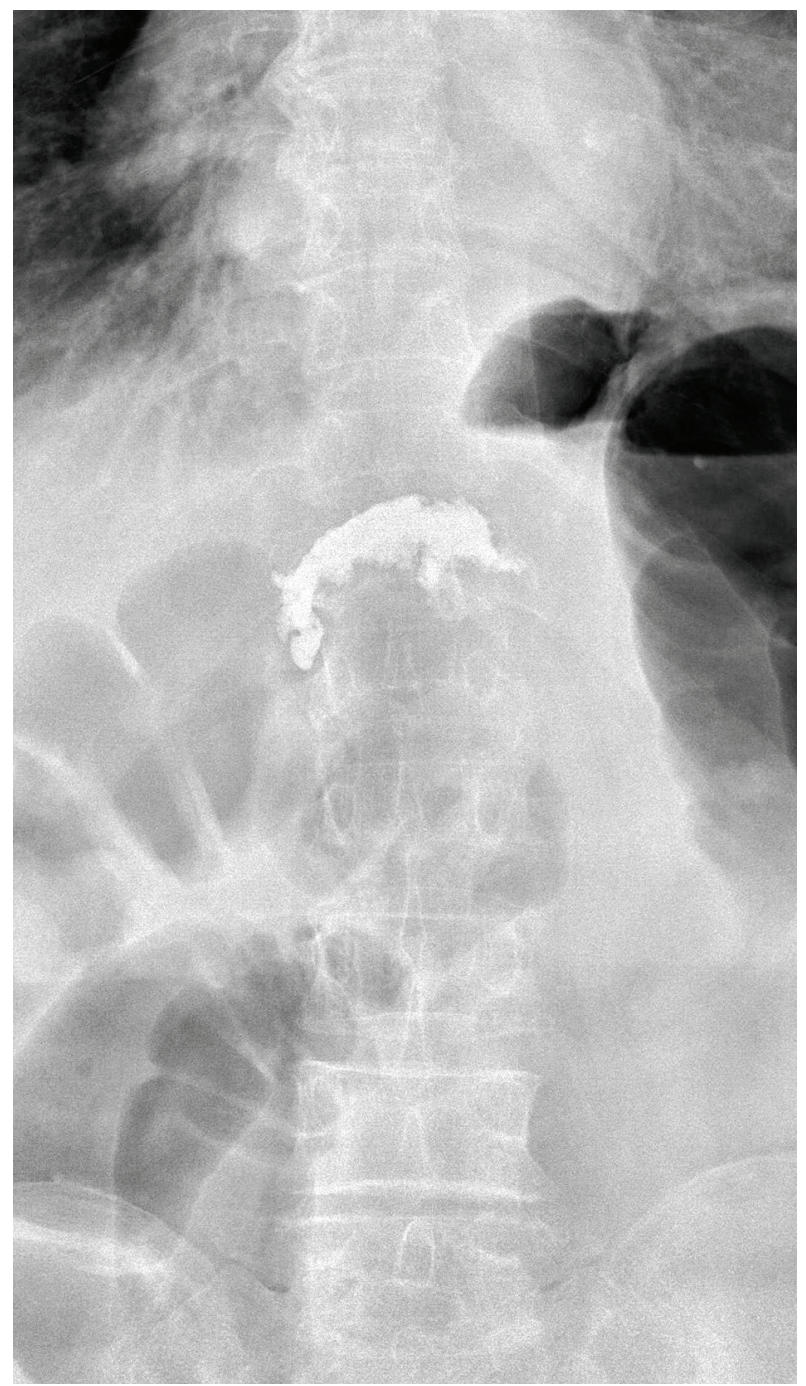

Fig. 2A, 2B. Cement extravasation into the vertebral canal and the adjacent neuroforamen 
are no complications, we mobilize and discharge the patient no later than the second postoperative day. The pain dynamics is followed up using visual analogue scale (VAS) preoperatively and postoperatively. In two patients we found cement extravasation into the vertebral canal and the adjacent neuroforamen, with new postoperative radicular syndrome with no motor weakness, corresponding to the PV level (Fig. $2 \mathrm{~A} / 2 \mathrm{~B})$.

In these two cases, we did hemilaminectomy with arthrotomy and foramenotomy with subsequent careful resection of the consolidated PMMA located in the neuroforamen.

\section{RESULTS}

The investigated cohort was comprised of 56 patients who have had PV at a total of 66 levels. Of them, $69.7 \%$ (46/66) were treated due to osteoporotic vertebral collapse, $21.2 \%(14 / 66)$ were neoplastic fractures and the remaining $9.1 \%(6 / 66)$ were traumatic fractures. Women had a prevalence in the osteoporotic fractures (24/17), while men had a prevalence in the neoplastic fractures (8/4). Similar to other investigated series, compression fractures addressed with $\mathrm{PV}$ are the most common in the thoraco-lumbar region Th11-L2 - 42.4\% (28/66). The mean PMMA amount used for the PV was 5cc (2-10).

Cement extravasation was encountered in $29 / 66$ levels (43.9\%). In 20 of the cases the extravasation was found to be vascular (Fig. 3A) and in 9 cases it was nonvascular. The most common vascular leakage is in the paravertebral venous system, with the neoplastic compression fractures found to be more commonly complicated by an intravascular leak (12/14) (Fig. 3B). One of the cases was complicated by pulmonary cement embolism (Fig. 4). Avascular cement leakage alongside the needle trajectory was found in 2 cases (Fig. 5), in the paravertebral soft tissues - in 4 cases (Fig. 6), in the adjacent disk via the
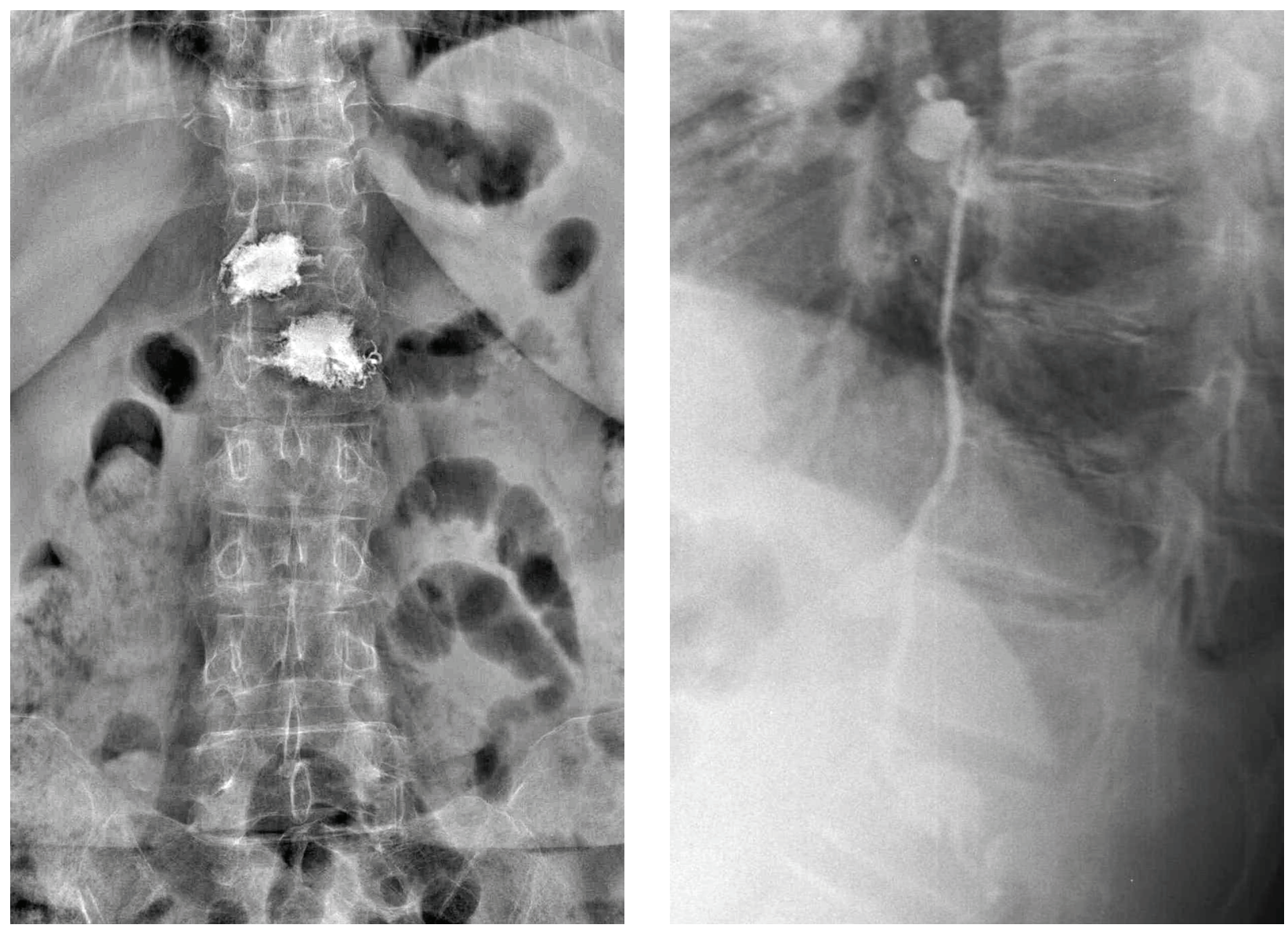

Fig. 3A, 3B. Non-vascular and vascular leakage in the paravertebral venous system 


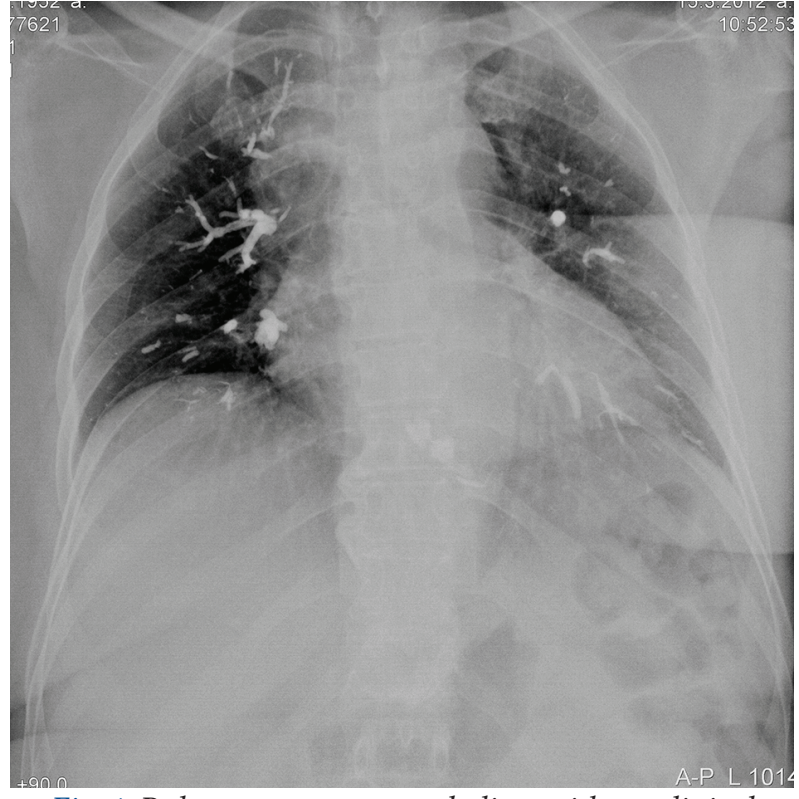

Fig. 4. Pulmonary cement embolism without clinical sequelae

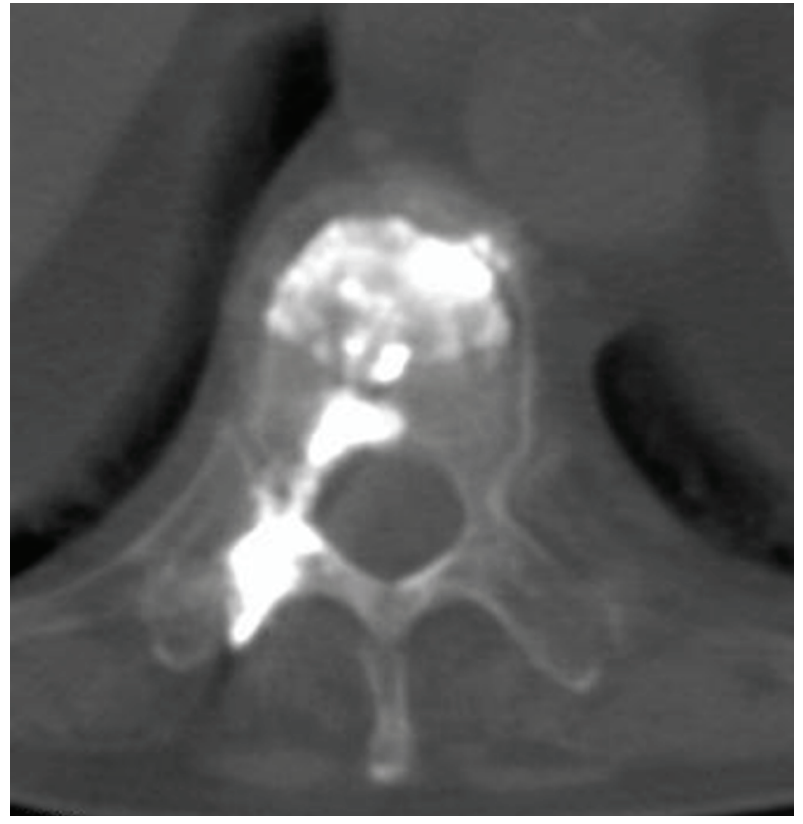

Fig. 5. Avascular cement leakage alongside the needle trajectory

endplate - in 1 case (Fig. 7), and to the spinal canal in 2 cases (Fig. 8).

In the immediate postoperative period, a significant pain alleviation was registered in 30 cases (53.6\%), and moderate pain reduction - in 15 (26.8\%). In 9 of the patients (16.1\%), the pain intensity had no change, but in some of the cases it got worse. The

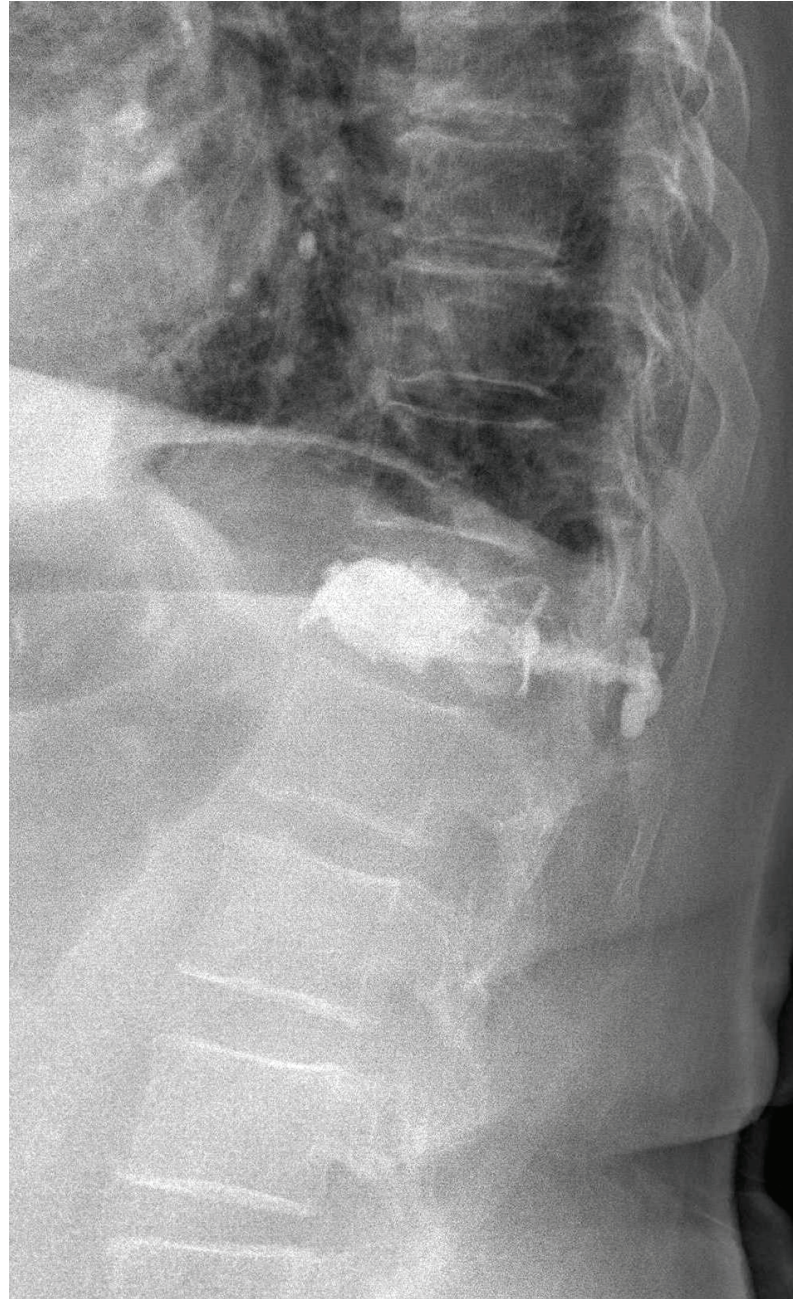

Fig. 6. Cement leakage in the paravertebral soft tissues

mean pre- and postoperative values were 7.5 and 3 , respectively $(\mathrm{p}<0.001)$.

Symptomatic deterioration and complications were found in 9 patients. In 7 of them, the pain syndrome was controlled with a conservative treatment for 7-10 days. In 2 of the patients with complications, the treatment included surgical decompression with a very good postoperative result.

\section{DISCUSSION}

After its introduction 20 years ago, PV in VCF is now considered safe and is well accepted by the patients. In the last decade, many investigations demonstrating the benefits of the procedure became available. It is now considered an easy to perform procedure with a success rate reaching up to $95-97 \%$ $(9,12)$. The indications for the procedure now com- 


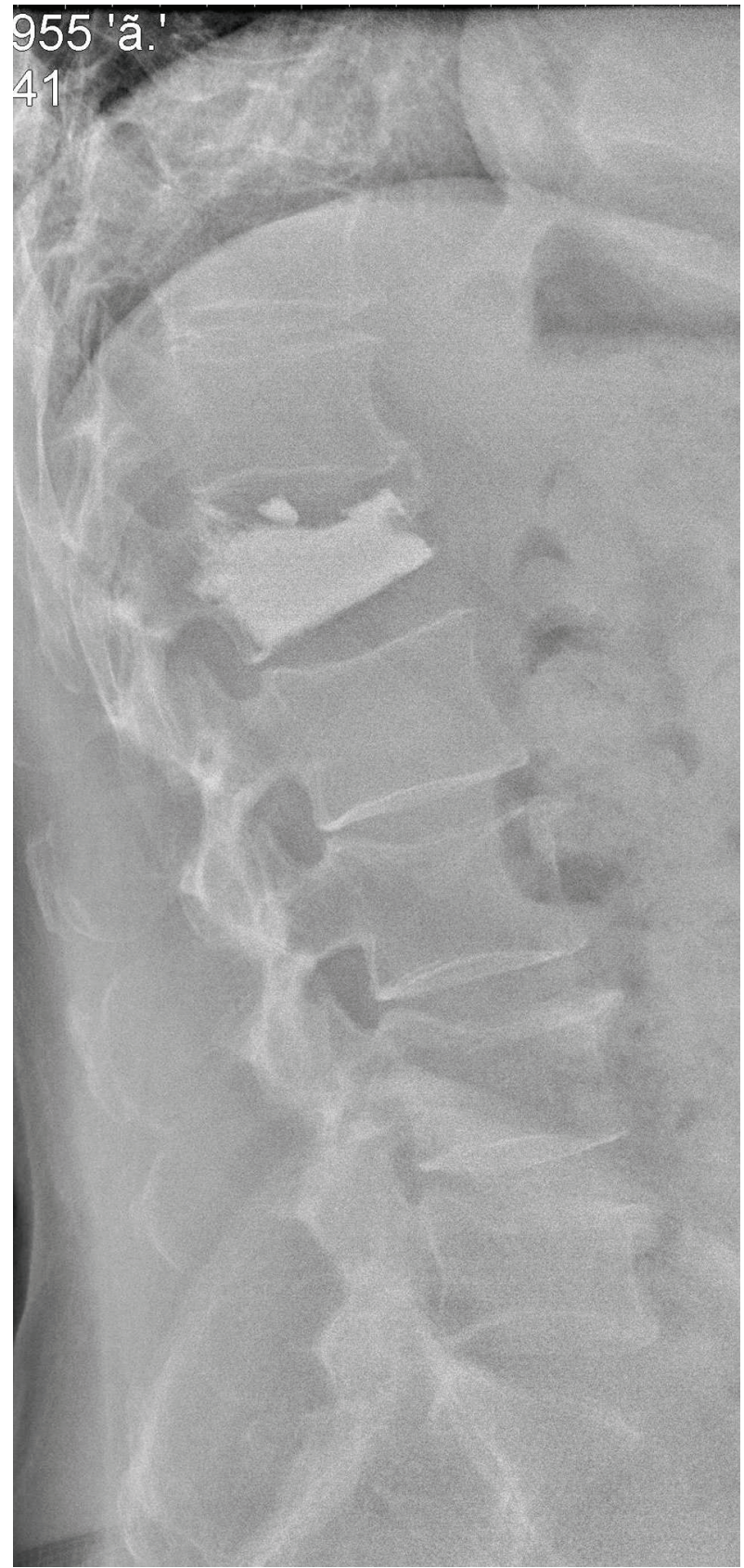

Fig. 7. Cement leakage in the adjacent disk via the endplate

prise metastatic vertebral lesions, myeloma, osteoporotic and acute vertebral compression fractures.

The fast and effective control of the pain syndrome in over $90 \%$ of the cases also contributes to the popularity of the procedure, as well as the biomechanical stability and collapse, and the deformity resistance of the level treated with PV $(1,2,9,15)$. Finally,

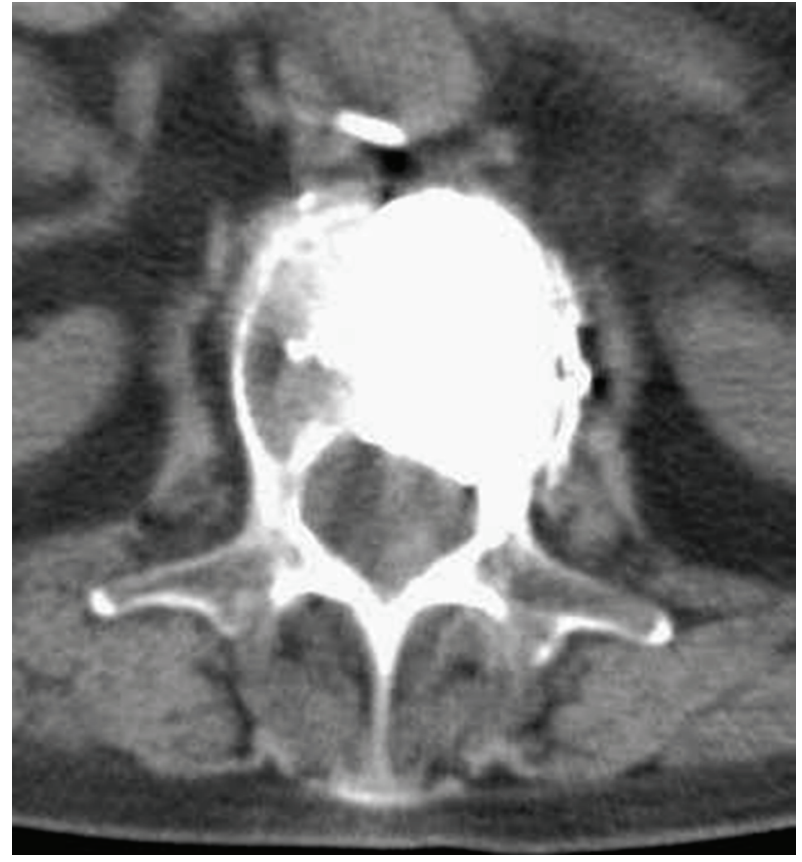

Fig. 8. Cement leakage in the spinal canal

many authors also emphasize the short hospital stay and the low procedure cost $(2,7,14)$.

Patient selection and the proper indication application is are the key factors for optimizing the results and minimizing the complications.

Although the minimal cement extravasation is not considered to be a complication as it is usually clinically silent, we have also counted the cases with minimal cement leakage as unwanted events, which could necessitate conservative symptomatic treatment, especially in a case of transient postoperative radiculopathy or axial back pain. According to some authors $(7,8,16)$, epidural, intradiscal, paraspinal and venous cement extrusion could appear in up to $88 \%$ of the cases, especially if evaluated on postoperative CTs. Layton et al. (8) published one of the largest series in year, analyzing the results of 1000 treated levels, of which $84 \%$ osteoporotic, $11 \%$ neoplastic and 5\% traumatic fractures, or hemangiomas. Authors report that although the complication rate is very low (1-2\%), a cement leakage is documented in $25 \%$. Lin et al. (19) report 18/38 patient with cement migration in the disk. They also report a higher risk for adjacent vertebral body fracture. Brodano et al. (9) found $7.4 \%$ cement leakage, analyzing 59 patients with treated 94 levels. The cement leak was consid- 
ered as a minimal complication without vascular and neurologic sequelae.

Barragan-Campos et al. (17), in a series of 117 patients with spinal metastases, have performed PV on 304 levels. In the course of the procedure, the authors documented 423 extravertebral leaks of PMMA, with a mean 2 (1-5) on a level. The majority of the leaks are vascular - leaks to the venous system. The remaining ones (21.5\%) are leaks following the needle trajectory, in the paravertebral soft tissues or the adjacent disk. All these technical accidents caused clinically expressed complications in only 8 cases $(6.8 \%)-6$ local and 2 systemic.

The patient cohort investigated by us is in general following the pattern of the technical incidents and complications reported in the literature $(2,4,6,13,16,17,19-25)$. Apart from some rare complications like infections, fatty emboli, incidental durotomies, rib fractures, etc., we have seen the majority of the complications reported by the other authors. The majority of the investigations are focused on a specific etiology like osteoporosis or neoplastic disease. Our group has all the variety of patients irrespective of the initial pathologic process. We have not encountered serious complications like infections, permanent neurologic deficit or mortality, although we have a case with pulmonary embolism with cement and a case with massive extravasation of the cement in the paravertebral veins, all those, however, without clinical sequelae.

We believe that the most serious complication from a clinical point of view is the epidural or foraminal migration of PMMA, which could cause a damage of the spinal cord or the nerve roots. This could happen if one of the following is present: fracture line compromising the posterior wall of the vertebral body; via the basivertebral veins; through the internal anterior venous plexus, via the canal made with the needle, going in a wrong direction $(6,13)$. The damage is mostly caused by direct neural compression and could cause severe radicular symptoms and neurologic deficit.

Furthermore, a harmful effect could be expected if the migrated bone cement, reaching temperature of $50-112^{\circ} \mathrm{C}$ for 4 minutes, gets in contact with the neural structures. This could cause thermal trauma or even thermal necrosis of the neural structures that are in direct contact $(1,2,13,17)$. The majority of the authors pay attention also to the cement viscosity, preferring a more viscous or partially polymerized substance injected via a wider needle $(3,4,18,20)$.

The liquid cement with lower consistency is more convenient to use, but also more dangerous, having a higher tendency to leak out to the venous system, fracture line, spinal canal or even reaching the pulmonary artery, causing severe systemic complications. Usually cement leakage to the spinal canal is picked up on the intraoperative X-rays, using image intensifiers or on the postoperative X-rays. It is well known now that the sensitivity of CT scanners is twice as high as the sensitivity of X-rays $(8,16)$. Hence, the patients with postoperative radicular pain or neurologic deficit should be urgently examined with CT scans with the view of possible decompression. The most commonly recommended salvaging procedure is laminectomy. Yang S-C et al. (4) examined 22 patients post-PV who had been operated on to revise the levels treated with PV. In 9 patients, the revisions were necessitated by bad cement augmentation. The authors used anterior, posterior or a combined surgical technique. In our 2 cases of surgical revision, we have used a posterior surgical approach with hemilaminectomy, arthrotomy, pediculotomy and foraminotomy. The wide approach allows the migrated cement to be easily removed without retracting the spinal cord. However, in case of wide decompression, a subsequent stabilizing instrumented fusion surgery might be necessary. In our study, the cases with mild radicular pain or axial vertebral pain related to unwanted cement migration are usually transient and easy to control with pain killers for several days. In that respect, our real complication rate is $3 \%(2 / 66)$, which corresponds well to the complication rate reported by other authors. With the view of reducing the risk of complications and unwanted events in PV, we believe that the procedure should be performed by experienced surgeons who are well familiar with the possible complications in details and who could immediately proceed with decompressive surgery, if needed. Respecting the safe technique, we recommend avoiding a breach of the medial pedicle wall or spinal canal. The optimal viscosity of the cement is also crucial. Regular intraoperative X-ray monitoring, while the cement is injected in the vertebral body and immediate stop when reaching the 
posterior $1 / 4$ of the body or leakage out of the body, is also recommended.

\section{CONCLUSION}

Based on our results, we have found convincing evidence that the PV with PMMA is a safe and effective method for treating spinal compression fractures with different etiology. The risk of unwanted events and clinically significant complications during the course of the procedure is relatively low when it is performed by experienced surgeons.

\section{REFERENCES}

1. Lieberman I. Vertebral Augmentation for Osteoporotic and Osteolytic Vertebral Compression Fractures: Vertebroplasty and Kyphoplasty Advances in Spinal Stabilization. Basel 2003;16: 240-250.

2. Phillips FM. Complications of Vertebroplasty and Kyphoplasty Complications of Pediatric and Adult Spinal Surgery Marcel Dekker, New York 2004:593-614.

3. Kostuik JP. Fractures of the cervical, thoracic, and lumbar spine. Marcel Dekker New York; 2002:635-654.

4. Yang S-C, Chen W-J et al. Revision strategies for complications and failure of vertebroplasties. Eur Spine J 2008;17:982-988.

5. Ha et al. Revision Surgery after Vertebroplasty or Kyphoplasty Clinics in Orthopedic Surgery. 2010; (2) 4:203-208.

6. Wu C-C, Lin M-H, Yang S-H et al. Surgical removal of extravasated epidural and neuroforaminal polymethylmethacrylate after percutaneous vertebroplasty in the thoracic spine. Eur Spine J 2007;16 (3):S326-S331.

7. McGirt MJ, Parker SL, Wolinsky J-P et al. Vertebroplasty and kyphoplasty for the treatment of vertebral compression fractures: an evidenced-based review of the literature. The Spine Journal 2009;(9) 501-508.

8. Layton KF, Thielen KR, Koch CA et al. Vertebroplasty, First 1000 Levels of a Single Center: Evaluation of the Outcomes and Complications. AJNR Am J Neuroradiol.2007;28:683- 89.

9. Brodano GB, Amendola L, Martikos K et al. Vertebroplasty: benefits are more than risks in selected and evidence-based informed patients. A retrospective study of 59 cases. Eur Spine J 2011; 20:1265-1271.
10. Galibert P, Deramond H, Rosat P, Le Gars D. Preliminary note on the treatment of vertebral angioma by percutaneous acrylic vertebroplasty. Neurochirurgie. 1987;33(2):166-8.

11. Marthis JM Percutaneous Vertebroplasty: Complication Avoidance and Technique Optimization. AJNR Am J Neuroradiol. 2003;24:1697-1706.

12. Tomycz ND, Gerszten PC. Minimally Invasive Treatments for Metastatic Spine Tumors: Vertebroplasty, Kyphoplasty, and Radiosurgery Neurosurg Q. 2008;18:104-108.

13. Teng MMH, Cheng $\mathrm{H}$, No DM. Intraspinal Leakage of Bone Cement after Vertebroplasty: A Report of 3 Cases. AJNR Am J Neuroradiol 2006;27:224-29.

14. Christie SD. Vertebroplasty and Kyphoplasty Atlas of Neurosurgical Techniques Thieme New York 2006:866-875.

15. Nairn RJ, Binkhamis S, Sheikh A. Current Perspectives on Percutaneous Vertebroplasty: Current Evidence/Controversies, Patient Selection and Assessment, and Technique and Complications. Radiology Research and Practice 2011; doi:10.1155/2011/175079:1-10.

16. Mohit AA, Douglas O. Percutaneous Vertebral Augmentation in Pathologic Fractures. Curr Opin Orthop 2007;18:221-225.

17. Barragan-Campos HM, Vallee J-N et al. Complications of Vertebroplasty for Metastasis. Radiology 2006;(238)1:354-362.

18. Nazar A. Al-Naksabandi. Percutaneous vertebroplasty complications. Ann Saudi Med. 2011; 31(3): 294-297.

19. Lin EP, Ekholm S. et al.Vertebroplasty: Cement Leakage into the Disc Increases the Risk of New Fracture of Adjacent Vertebral Body.AJNR Am J Neuroradiol 2004;25:175-180.

20. Choe DH, Marom EM, Ahrar K et al. Pulmonary Embolism of Polymethyl Methacrylate During Percutaneous Vertebroplasty and Kyphoplasty. AJR 2004;183:1097-1102.

21. Lee CB, Kim HS, Kim YJ. Pyogenic Spondylitis after Vertebroplasty. Asian Spine Journal 2007; (1) 2:106-109.

22. Cho D-Y, Lee W-Y et al. Treatment of thoracolumbar burst fractures with polymethil methacrylate vertebroplasty and short-segment pedicle screw fixation. Neurosurgery 2003;53:1354-1361. 
Surgical Complications and Unwated Events in the Modern Percutaneous Vertebroplasty Treatment

23. Nakano M, Hirano N, Zukawa M et al. Vertebroplasty Using Calcium Phosphate Cement for Osteoporotic Vertebral Fractures: Study of Outcomes at a Minimum Follow-up of Two Years. Asian Spine Journal 2012; (6)1:34 42.

24. Al-Ali F, Barrow T, Luke K. Vertebroplasty: What Is Important and What Is Not. AJNR Am J Neuroradiol 2009;30:1835-39.

25. Hiwatashi A, Westesson P-LA. Vertebroplasty for Osteoporotic Fractures with Spinal Canal Compromise. AJNR Am J Neuroradiol.2007; 28:690 -92. 